\title{
Genetic Diversity and Population Structure of Three Strains of Indigenous Tswana Chickens and Commercial Broiler Using Single Nucleotide Polymormophic (SNP) Markers
}

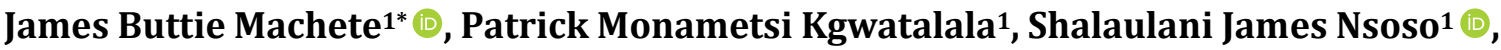 \\ Nompilo Lucia Hlongwane'2, John Cassius Moreki1 ${ }^{10}$
}

\author{
${ }^{1}$ Department of Animal Science and Production, Botswana University of Agriculture and Natural Resources, Gaborone, Botswana \\ ${ }^{2}$ Biotechnology Platform, Agricultural Research Council, Pretoria, South Africa
}

Email: ^buttiemachete@gmail.com

\begin{abstract}
How to cite this paper: Machete, J.B., Kgwatalala, P.M., Nsoso, S.J., Hlongwane, N.L. and Moreki, J.C. (2021) Genetic Diversity and Population Structure of Three Strains of Indigenous Tswana Chickens and Commercial Broiler Using Single Nucleotide Polymormophic (SNP) Markers. Open Journal of Animal Sciences, 11, 515-531. https://doi.org/10.4236/ojas.2021.114035
\end{abstract}

Received: June 4, 2021

Accepted: August 22, 2021

Published: August 25, 2021

Copyright $\odot 2021$ by author(s) and Scientific Research Publishing Inc. This work is licensed under the Creative Commons Attribution International License (CC BY 4.0).

http://creativecommons.org/licenses/by/4.0/ (c) (i) Open Access

\begin{abstract}
The Tswana chicken is native to Botswana and comprises strains such as the naked neck, normal, dwarf, frizzled, and rumples. The origins of the different strains of Tswana chicken remain unknown and it is not yet clear if the different strains represent distinct breeds within the large Tswana chicken population. Genetic characterization of different strains of Tswana chickens using SNP arrays can elucidate their genetic relationships and ascertain if the strains represent distinct breeds of Tswana chicken population. The aim of this study was therefore to investigate population structure and diversity and to estimate genetic distances/identity between the naked neck, normal and dwarf strains of Tswana chickens. A total of 96 chickens (normal strain ( $\mathrm{n}=$ 39), naked neck strain $(\mathrm{n}=32)$, dwarf strain $(\mathrm{n}=13)$ and commercial broiler $(\mathrm{n}=12))$ were used in the study. SNP genotyping was carried out using the Illumina chicken iSelect SNP 60 Bead chip using the Infinium assay compatible with the Illumina HiScan SQ genotyping platform. The observed heterozygosity $\left(\mathrm{H}_{\mathrm{o}}\right)$ values were $0.610 \pm 0.012,0.611 \pm 0.014,0.613 \pm 0.0006$ for normal, naked neck and dwarf strains of Tswana chickens respectively and averaged $0.611 \pm 0.016$ across the three strains of Tswana chickens compared to Ho of $0.347 \pm 0.023$ in commercial broiler chicken. The expected heterozygosity $\left(\mathrm{H}_{\mathrm{e}}\right)$ values were $0.613 \pm 0.00012,0.614 \pm 0.00013,0.608 \pm 0.00021$ for normal, naked neck and dwarf strains of Tswana chickens respectively and averaged $0.612 \pm 0.00015$ across the three strains of Tswana chickens compared to $\mathrm{H}_{e}$ of $0.577 \pm 0.00022$ in commercial broiler chicken. Principal component analysis (PCA) was used to get an insight into the population
\end{abstract}


structure of indigenous Tswana chickens. The first two principal components revealed a set of three clusters. The normal strain of Tswana chicken and commercial broiler clustered together in one group. The dwarf strain clustered separately in one group and the naked neck and normal strains clustered together in the last group. The separate clustering of the dwarf strain from the rest of Tswana chicken strains suggests significant genetic uniqueness of the dwarf strain and very close genetic similarities between the normal and naked neck strains. The clustering pattern was confirmed by less genetic differentiation and less genetic distances between the naked neck and normal strains of Tswana chicken than between the two strains and the dwarf strain of Tswana chicken.

\section{Keywords}

Genetic Distances, Genetic Diversity, Indigenous Tswana Chickens, Population Structure, SNPs

\section{Introduction}

Chickens have more distinct use and benefits to the household in different developing countries [1]. Indigenous Tswana chickens are one of the most important livestock species which provide most of the protein in the form of eggs and meat and improve the rural economy of subsistence farmers through sales of eggs as well as live birds. The chicken products (meat and eggs) are preferred by many people in rural areas due to their taste, leanness, palatability, and appropriateness for exceptional dishes [2] [3] [4]. Indigenous Tswana chickens contribute to food security in the rural areas and also generate emergency cash income for women since indigenous Tswana chickens are mostly owned by women. The Tswana chickens play a significant role in the sociocultural life of the rural population. Indigenous chickens also have roles in traditional ceremonies and other customs as gift payments [5]. Nonetheless, the growth rate of indigenous Tswana chickens is relatively low as compared to the commercial broiler due to poor nutritional support, poor housing, poor health care, and lack of selection for growth potential under the scavenging management system [6].

Generally, indigenous chickens are kept in small flocks (2 to 20 chickens) of varied ages under traditional scavenging management system with basic supplementary feeding, housing, and healthcare [6]. They possess important positive characteristics such as hardiness, the ability to tolerate the harsh environmental condition, and poor husbandry practices (climate, handling, watering, and feeding) without much loss in production [7]. Indigenous chickens grow slowly and normally require up to 12 months to reach slaughter age [8] and age at first lay is approximately 7 months [9]). [10] Desta reported a mating ratio of 1 cock to 2 hens for indigenous chickens' population in Ethiopia; but the recommended mating ratio is 1 cock to 5 - 10 hens [9].

Indigenous Tswana chicken population comprises several strains/ecotypes 
such as the normal, naked neck, dwarf, frizzled, and rumples strains [11] [12]. The dwarf, frizzled and rumpless strains are found at a relatively low frequency within the indigenous Tswana chicken population and the normal strain is by far the most common strain [13]. [14] Machete et al. evaluated quantitative traits in the naked neck, normal, dwarf, rumples, and frizzled strains of Tswana chickens under traditional free-running management system and found similar quantitative traits with the exception of shank length and shank circumference in the dwarf strain compared to the other four strains. [6] Kgwatalala et al. reported similar body weights between the naked neck and normal strains of Tswana chicken and significantly lower body weights in the dwarf strain from 4 to 14 weeks of age under an intensive management system. Similarly, [15] Kgwatalala et al. reported similar preslaughter live weight, carcass weight, dressing percentage, and primal cuts weights between the naked neck and normal strain of Tswana chickens and significantly lower pre-slaughter live weight, carcass weight, dressing percentage, and primal cuts weights in the dwarf strain. It is generally accepted that performance in various traits of economic importance is the function of both the genotype and the environment. Do the similarities in performance between the naked neck and normal strains of Tswana chickens outlined above reflect the underlying genetic similarities? Is the deviation in performance of the dwarf strain compared to both the naked neck and normal strains of Tswana chicken a reflection of its genetic distinctness? To date, no genetic characterization studies have been carried out on different strains of Tswana chickens and it is still unclear if the strains represent distinct breeds. The objectives of the study were therefore to investigate population structure and diversity and to estimate genetic distances/identity between the naked neck, normal and dwarf strains of Tswana chickens.

\section{Methods and Materials}

\subsection{Study Population}

A total of 96 mixed indigenous Tswana chickens were used in the study. The indigenous chickens from the Southern part of Botswana were represented by normal strain $(n=39)$, naked neck strain $(n=32)$, dwarf strain $(n=13)$ of Tswana chickens kept under traditional free-running management system and commercial broiler $(n=12)$. The chickens used were approximately six months of age or older as per the information provided by the owners. Information on sampling locations and the number of samples per sampling location is available from Table 1.

\subsection{Collection of Blood Samples}

Blood samples were collected from the medial metatarsal vein located on the leg of a chicken better suited for puncture using a 23-gauge, 1 -in needle. The alternative site for blood collection was the brachial vein on the wings and for puncture, feathers in this area were plucked for smooth insertion of needle on the 
Table 1. Locations where indigenous Tswana chickens were sampled and number of samples per location in Kweneng and southern districts of Botswana.

\begin{tabular}{ccccc}
\hline \multirow{2}{*}{ Sampling location } & District & Normal & No. of samples per location & \multirow{2}{*}{ Dwarf } \\
\cline { 4 - 5 } Sojwe & Kweneng & 8 & Naked neck & 7 \\
Kaudwane & Kweneng & 2 & 4 & 0 \\
Maboane & Kweneng & 4 & 3 & 2 \\
Malwelwe & Kweneng & 4 & 0 & 2 \\
Kweneng & Kweneng & 3 & 3 & 1 \\
Keng & Southern & 5 & 4 & 0 \\
Seherelela & Southern & 4 & 3 & 0 \\
Thankane & Southern & 2 & 4 & 0 \\
Lerolwane & Southern & 3 & 3 & 13 \\
Magotshwane & Southern & 4 & 32 & 0 \\
TOTAL & & 39 & & 4 \\
\hline
\end{tabular}

veins of interest. All blood in vacutainer tubes containing EDTA and kept under cool environment of ice packs until they reach the laboratory where blood samples were kept at $-20^{\circ} \mathrm{C}$ until DNA extraction.

\subsection{DNA Extraction}

$24 \mu \mathrm{l}$ of NucleoMag ${ }^{\oplus}$ B-Beads and $360 \mu \mathrm{l} \mathrm{MB2}$ Buffer were then added to the square-well Block and mixed by pipetting up and down, shaking for 5 minutes at room temperature. Magnetic beads were then separated against the wells by placing the square-well block on the NucleoMag SEP magnetic separator for at least 2 minutes. The supernatant was then removed from the wells and discarded by pipetting. The square-well block was then removed from the NucleoMag SEP magnetic separator and $600 \mu \mathrm{l}$ of MB3 buffer was added to each of the wells, accompanied by shaking to completely resuspend the beads. Magnetic beads were again separated against the wells by placing the square-well block on the NucleoMag SEP magnetic separator for at least 2 minutes. The supernatant was again removed and discarded by pipetting.

The square-well block was removed again from NucleoMag SEP magnetic separator. $600 \mu \mathrm{l}$ of MB4 buffer was then added to each of the wells and the beads were resuspended by shaking for 5 minutes. Magnetic beads were again separated by placing the square-well block on the NucleoMag SEP magnetic separator for at least 2 minutes and supernatant was removed and discarded by pipetting. $900 \mu \mathrm{l}$ of MB5 buffer was then added to each of the wells while the beads were still attracted to magnets. After an incubation period of 50 seconds, the supernatant was aspirated and discarded. The square-well block was then removed from the NucleoMag SEP magnetic separator. $50 \mu \mathrm{l}$ of DNA elution buffer was then added to each of the wells and shaking for 10 minutes at $56^{\circ} \mathrm{C}$ to resuspend 
the beads. Magnetic beads were again separated by placing the square-well block on the NucleoMag SEP magnetic separator for at least 2 minutes. The supernatant containing purified genomic DNA was then transferred to the elution plate for SNP genotyping.

\subsection{SNP Genotyping and Data Preparation}

SNP genotyping was carried out at Agricultural Research Council-Biotechnology Platform in Pretoria according to the protocols described by [16] Khanyile et al. Briefly, SNP genotyping was carried out using the Illumina chicken iSelect SNP 60Bead chip using the Infinium assay compatible with the Illumina HiScan SQ genotyping platform. This Infinium assay is designed to analyze a large number of SNPs at many loci concurrently through multiplexing [17] http://www.illumina.com. SNP calling was done using Illumina Genome Studio v2.0. The genotype input file was converted into a PLINK (v1.07) [18] Purcell et al. input file using a plug-in compatible with Genome Studio program. SNP quality control was done in a series of steps depending on population genetic parameters estimated.

\subsection{Population Genetic Parameters}

An original data set consisting of all four populations of Tswana chickens (naked neck, Normal and Dwarf populations) was filtered for SNPs that had minor allele frequency (MAF) $\leq 0.02$ and this resulted in a total sample of 82 chickens across the three populations. There were 54,293 SNPs available to estimate observed and expected heterozygosity indices ( $\mathrm{Ho}$ and $\mathrm{He}$ ) and the inbreeding coefficient of each population. PLINK (v1.07) software [17] was used to estimate observed and expected heterozygosity, inbreeding coefficient and minor allele frequency distribution per population using the comprehensive data set before pruning for MAF. Bins were set for minor allele frequencies of $0-0.05,0.05$ $0.1,0.1-0.2,0.2-0.3,0.3-0.4$ and $0.4-0.5$ and the proportion of SNPs per bin was calculated by dividing the number of markers per bin by the total number of markers included in the MAF estimation according to [16] Khanyile et al.

\subsection{Population Structure}

A complete SNP data set with all four populations was filtered to remove SNPs that were on sex chromosomes or had their positions unmapped. Markers with missing data $>5 \%$; that had a MAF $\leq 2 \%$ or were monomorphic were removed from the complete data set. SNPs that were in high linkage disequilibrium at a threshold of $L D \geq 0.2$ were also filtered out of the complete data set. Individuals with missing genotypes of more than $5 \%$ and those that were closely related, as inferred by a kinship estimator $\geq 0.45$ were also excluded from the analysis.

A principal component analysis (PCA) was then performed to establish relationships among different strains of Tswana chickens and the commercial broiler line using the Golden helix SNP variation suit (SVS) version 8.1 [19]. Fur- 
thermore, the Admixture 1.23 software [20] was used to estimate the most probable number of ancestral populations based on the SNP genotype data as described by [16] Khanyile et al. Admixture was run from $\mathrm{K}=2$ to $\mathrm{K}=4$ and the optimal number of clusters (K-value) was determined as that which had the lowest cross-validation error (CV error).

\subsection{Population Differentiation and Genetic Distances}

Pairwise identity by state (IBS) distances between all four chicken populations (naked neck, normal and dwarf strains of Tswana chicken and the commercial broiler) were calculated using PLINK v1.9. Genetic distances between the four populations were evaluated based on Nie's (1987) unbiased. Genetic distance uses the R-package [21]. To evaluate pair-wise genetic differentiation, the fixation index F st [22] 4 was calculated for all pairs of chicken populations.

\subsection{Linkage Disequilibrium}

Complete SNP data for the individual populations were filtered to remove SNPs on sex chromosomes or those were not mapped, those with $\mathrm{MAF} \leq 5 \%$, those that deviated from Hardy-Weinberg equilibrium (HWE) $(\mathrm{P} \leq 0.001)$ and individual chickens with missing genotypes $(>5 \%)$ and those with very close kinship (IBD $\geq 0.45$ ) using PLINK (v1.07) [18]. After all quality control measures 46,084 out of 48,054 in the normal strain, 45,080 out of 46,909 in the naked neck strain, 38,781 out of 42,804 in the dwarf strain of Tswana chickens, and 36,401 out of 39,739 in the commercial broiler were available for the estimation of linkage disequilibrium. The resultant individual population data sets after quality control measures were used in the estimation of linkage disequilibrium and associated measures.

Pairwise $\mathrm{r}^{2}$ estimation was used to measure LD between pairs of SNPs within a chromosome and population using PLINK (v1.07) program [18] 2007 for SNPs on chromosomes 1 - 28 that had passed quality control tests detailed above. According to [23] Lu et al., the $r^{2}$ measure, defined as the squared correlation coefficient of alleles at two loci was chosen because it is independent of allele frequency. Briefly, its calculation, considers two loci, $A$ and $B$, each locus having two alleles (denoted $A 1, A 2 ; B 1, B 2$, respectively) [24]. The frequencies of the haplotypes will then be denoted as $F 11, F 12, F 21$, and $F 22$ for haplotypes $A 1 B 1$, $A 1 B 2$ and $A 2 B 2$, respectively and as $F A 1, F A 2, F B 1$ and $F B 2$ for $A 1, A 2, B 1$ and $B 2$ alleles, respectively. From this, $r^{2}$ according to [16] Khanyile et al. were then calculated as shown in Formula (1) below:

$$
r^{2}=(f 11 f 22-f 12 f 21)^{2} / F A 1 F A 2 F B 1 F B 2
$$

PLINK by default only reports $r^{2}$-values above 0.2 and to allow reporting of all $r^{2}$-values observed in the populations, the $-r^{2}$-window-ldo option was used. An additional option, $-\mathrm{r}^{2}$-window-snp $5000 \mathrm{~kb}$ 10,000 described by [16] Khanyile et al., allowed for estimation of $r^{2}$ for SNP marker pairs separated by at most 5000 
SNPs and within a $10 \mathrm{MB}$ SNP interval.

\subsection{Effective Population Size}

The effective population size trends were estimated using the procedure described by [16] Khanyile et al. Briefly, the relationship between $N_{e}$, recombination frequency, and expected $\operatorname{LD}\left(r^{2}\right)$ was determined using the equation from [25] Corbin et al. shown in Formula (2):

$$
E\left[r_{a d j}^{2}\right]=\left(\alpha+4 N_{e} c\right)^{-1}
$$

where $\alpha=1$ when assuming no mutations and 2 if mutation was considered, $r_{a d j}^{2}=r^{2}-1 / 2 n, c$ was the recombination rate, and $n$ was the chromosomal sample size. The effective population size $N_{e}$ as $1 / 2 c$ generations, was estimated from the adjusted $r_{a d j}^{2}$ values related to a given genetic distance $d$ in Morgans, assuming $c=d$ [24]. For each pair of SNPs on each chromosome, recombination rate was estimated by converting physical marker interval length $x_{i}(\mathrm{MB})$ to the corresponding genetic length $c_{i}$ using the formula: $c_{i}=\bar{o}_{i} X_{i}$, where $\bar{o}_{i}$ is the average ratio of Morgans per kilo base pair on chromosome I, which was taken from physical lengths of the chicken genome v74 [26]. The genetic length of chromosomes was adopted from [27]. The $r^{2}-$ values range from 0 and 1 , whereby a zero value indicates uncorrelated SNPs while a value of one reflects SNPs that are perfectly correlated [24]. The trends in effective population sizes for each of the defined subpopulations were then estimated by setting bins at $10,20,40,60,100$, 200, 500, 1000, 2000 and $5000 \mathrm{~kb}$. The bins were designed to cover the genome in tens, hundreds, thousands and hundred thousand base pairs.

\section{Results and Discussion}

\subsection{Basic Population Genetic Parameters}

The observed heterozygosity $\left(\mathrm{H}_{\mathrm{o}}\right)$ values were $0.610 \pm 0.012,0.611 \pm 0.014,0.613$ \pm 0.0006 for normal, naked neck and dwarf strains of Tswana chickens respectively. There were no significant differences in $\mathrm{H}_{\mathrm{o}}$ between the three strains of Tswana chickens. The $\mathrm{H}_{\mathrm{o}}$ averaged $0.611 \pm 0.016$ across the three strains of Tswana chickens compared to $\mathrm{H}_{\mathrm{o}}$ of $0.347 \pm 0.023$ in commercial broiler chicken. The expected heterozygosity $\left(\mathrm{H}_{\mathrm{e}}\right)$ values were $0.613 \pm 0.00012,0.614 \pm$ $0.00013,0.608 \pm 0.00021$ for normal, naked neck and dwarf strains of Tswana chickens respectively. There were no significant differences in $\mathrm{H}_{e}$ between the three strains of Tswana chickens. The $\mathrm{H}_{\mathrm{e}}$ averaged $0.612 \pm 0.00015$ across the three strains of Tswana chickens compared to $\mathrm{H}_{\mathrm{e}}$ of $0.577 \pm 0.00022$ in commercial broiler chicken.

The $\mathrm{H}_{\mathrm{o}}$ and $\mathrm{H}_{\mathrm{e}}$ values for the three strains of indigenous Tswana chickens are similar with the $\mathrm{H}_{\mathrm{o}}$ and $\mathrm{H}_{\mathrm{e}}$ values found in indigenous chickens of Malawi, Zimbabwe and South Africa as reported by [16] Khanyile et al. Higher molecular diversity in indigenous Tswana chickens compared to commercial broiler chickens is consistent with [28] Al-Atiyat and Abudabos, who reported higher 
gene diversity in indigenous chickens of Jordan than in Ross broiler chickens $\left(\mathrm{H}_{\mathrm{e}}\right.$ of 0.54 vs 0.09 ). Higher genetic diversity in indigenous Tswana chickens than commercial broiler chickens might be due to inherent traditional breeding practices of natural and random mating of indigenous chickens. Indigenous Tswana chickens are also not subjected to intensive selection in various traits of economic importance which tends to promote diversity than uniformity. Lower genetic diversity in commercial broiler compared to indigenous Tswana chickens might be due to artificial selection for traits of economic importance such as meat production [28].

In the normal and naked neck strains of Tswana chickens, $\mathrm{H}_{\mathrm{o}}$ was less than $\mathrm{H}_{\mathrm{e}}$ while in the dwarf strain $\mathrm{H}_{o}$ was greater than $\mathrm{H}_{e}$ is indicating that the dwarf strain was significantly outbreed while the other two strains of Tswana chickens were inbred. In the commercial broiler chicken, $\mathrm{H}_{\mathrm{o}}$ was also less than $\mathrm{H}_{e}$ also indicating that the broiler chicken was inbred. The inbreeding coefficients (Fis) were positive for the normal, naked neck and commercial broiler and negative in the dwarf strain of Tswana chicken. Of all the four strains only the dwarf strain was therefore outbred. The commercial broiler had the highest levels of inbreeding compared to indigenous Tswana chickens. The three strains of indigenous Tswana chickens generally had lower inbreeding coefficients than indigenous chickens of Malawi, Zimbabwe and South Africa reported by [16] Khanyile et al.. Higher levels of inbreeding in commercial broiler chickens than in indigenous Tswana chickens were expected as inbreeding is part of the breed development process. Intensive selection during development of commercial broiler chickens reduced diversity and increased uniformity partially as result of inbreeding.

The minor allele frequency (MAF) was also presented in Table 2 for each population from generated data set since it provides information to differentiate between common and rare variants in the population. The analysis of SNP markers indicated an average minor allele frequency (MAF) of 0.266, 0.266, 0.241 and 0.259 in the normal, naked neck, dwarf and broiler strains, respectively.

\subsection{Population Structure Using Principal Component and Admixture Analysis}

\subsubsection{Population Structure}

Principal component analysis (PCA) was used to get an insight into the population structure of indigenous Tswana chickens. The first two principal components

Table 2. Percentage of polymorphic markers, within-population diversity and inbreeding coefficient of different chicken populations in Kweneng and Southern districts of Botswana.

\begin{tabular}{cccccccc}
\hline Population & $\mathrm{N}$ & Tested markers & Polymorphic SNPs $(\%)$ & $\mathrm{H}_{\mathrm{o}}$ & $\mathrm{H}_{\mathrm{e}}$ & Fis & Average MAF \\
\hline Normal & 39 & 48054 & $95.9(46084)$ & $0.610 \pm 0.012$ & $0.613 \pm 0.00012$ & 0.010 & $0.266 \pm 0.0006$ \\
Naked neck & 32 & 46909 & $96.1(45080)$ & $0.611 \pm 0.014$ & $0.614 \pm 0.00013$ & 0.007 & $0.266 \pm 0.0006$ \\
Dwarf & 13 & 42804 & $90.6(38781)$ & $0.613 \pm 0.023$ & $0.608 \pm 0.00021$ & -0.010 & $0.241 \pm 0.0006$ \\
Broiler & 12 & 39739 & $91.6(36401)$ & $0.347 \pm 0.023$ & $0.577 \pm 0.00022$ & 0.545 & $0.259 \pm 0.0007$ \\
\hline
\end{tabular}


revealed a set of three clusters. The normal strain of Tswana chicken and commercial broiler chicken clustered together in one group. Among the three strains of Tswana chickens, the dwarf strain clustered separately in one group and the naked neck and normal strains clustered together in the last group. The separate clustering of the dwarf strain from the rest of Tswana chicken strains suggests significant genetic uniqueness of the dwarf strain and very close genetic similarities between the normal and naked neck strains. For conservation purposes, the dwarf strain of Tswana chickens needs to be included in the conservation program as a separate strain while the naked neck and normal can be conserved as either one of the two. The genetic uniqueness of the dwarf strain of Tswana chicken relative to the normal and naked neck strains implies a possible different centre of Asian origin for the dwarf strain and common centre of origin for naked neck and normal strains of Tswana chickens.

The first principal component (PC) distinguishes, the commercial broiler from the rest of indigenous Tswana chicken strains while the second PC distinguishes the dwarf strain from the other two strains of indigenous Tswana chickens. The commercial broiler chicken clustered more closely with the normal strain of Tswana chickens than any other strains of indigenous Tswana chickens. The clustering together of commercial broiler and normal strain of Tswana chicken suggests high genetic similarities between the two probably because of their common centre of origin. According to [28] Al-Atiyat and Abudabos Asian indigenous chickens contributed to strains and lines used in the development of commercial broiler chickens and molecular genetic information suggests possible Asian centres of origin for African domestic chickens [29] Mwacharo et al. Another explanation is possible cross-breeding between normal strain of Tswana chickens and recently introduced chicken breeds of Asian origin under our free-range management system (Figure 1).

\subsubsection{Admixture Analysis}

The graphic results of the clustering analysis for $\mathrm{K}=2$ to 4 are illustrated in (Figure 2). Based on the visual inspection and admixture plot, the results indicate that the most likely partition was for $\mathrm{K}=3$ populations. The change in prediction error against $\mathrm{K}$ (Figure 3 ) indicates minimal improvement in model fitness between $\mathrm{K}=3$ and $\mathrm{K}=4$, suggesting that $\mathrm{K}=3$ describes the cluster number that best describes the populations under study.

At $\mathrm{K}=2$ the commercial broiler chicken separates from indigenous Tswana chickens while at $\mathrm{K}=3$ the dwarf strain of Tswana chickens separates from other strains (normal and naked neck) of Tswana chickens. From $\mathrm{K}=2$ analysis, it is apparent that the commercial broiler is not homogenous and contains significant admixture from the normal strain of Tswana chickens. At $\mathrm{K}=3$ the dwarf strain separates from other strains of Tswana chickens but displayed significant admixture or introgression from normal and naked neck strains of Tswana chickens probably because of interbreeding between the strains under traditional 


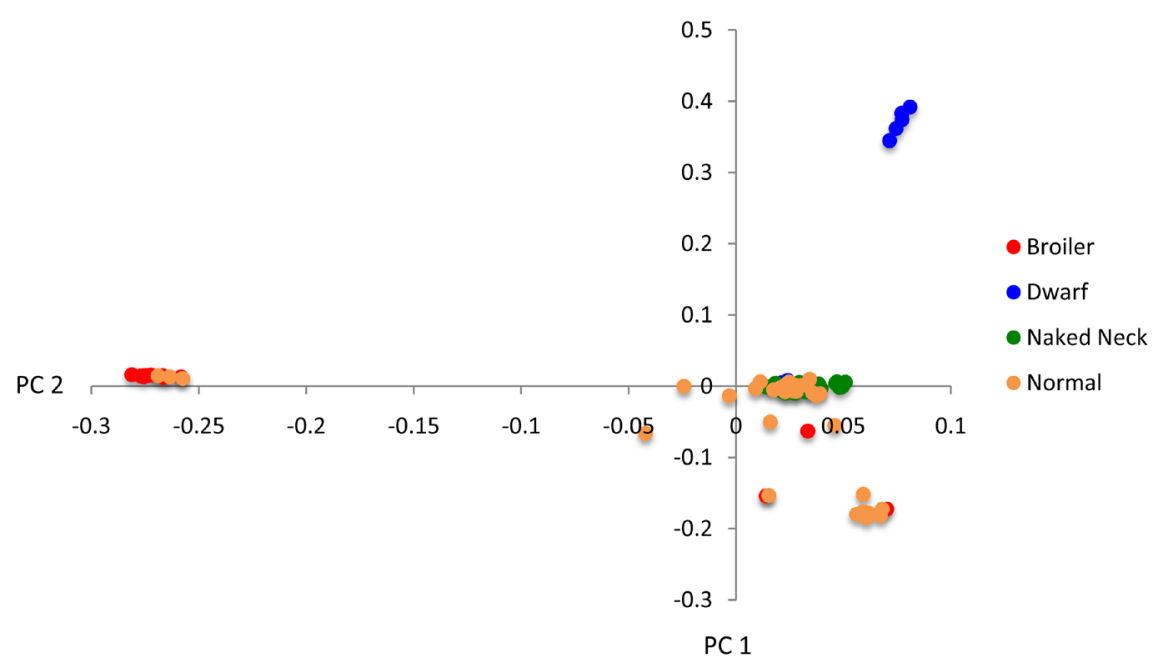

Figure 1. The genetic relationship between Tswana chicken strains using principal component analysis (PCA).

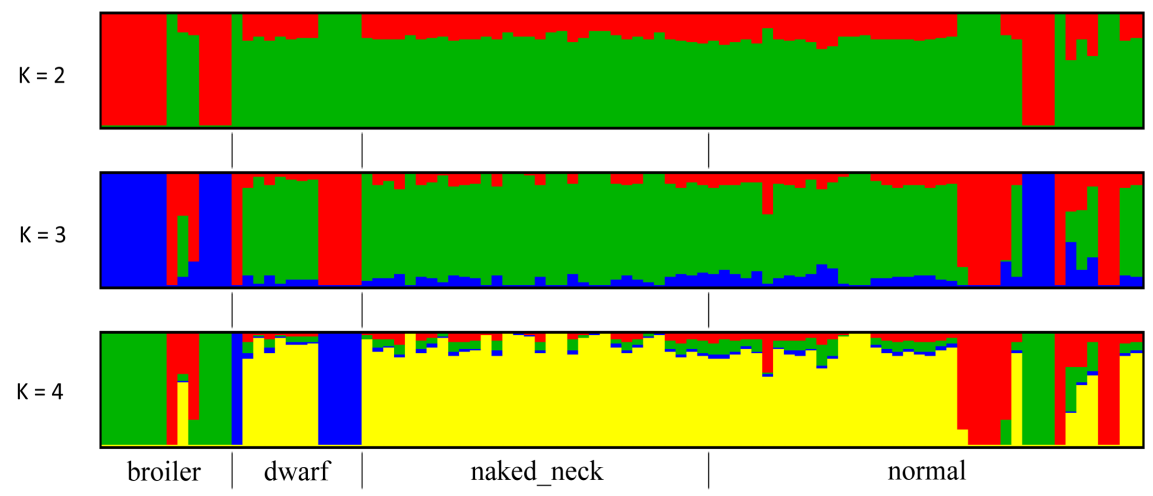

Figure 2. Population structures of normal, naked-neck, dwarf and broiler chickens based on admixture analysis.

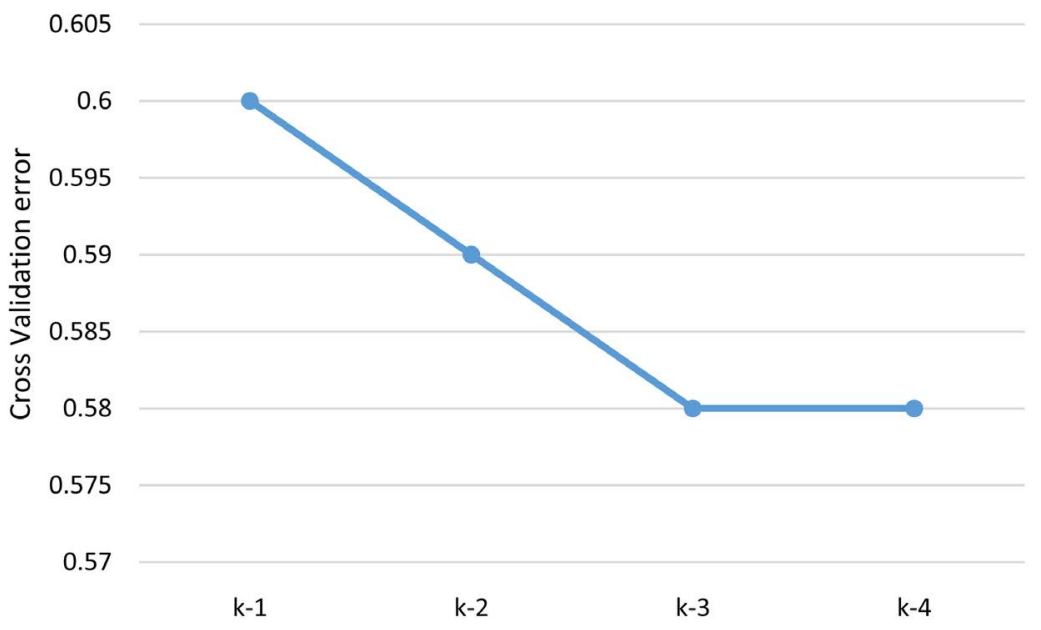

Figure 3. Optimal number of clusters according to cross-validation error.

free-running management system. Still at $\mathrm{K}=3$ naked neck and normal strains of Tswana cluster together as one distinct group. 
The lowest cross-validation error was observed at $\mathrm{K}=3$, which represented the number of ancestors in indigenous Tswana chicken strains and the commercial broiler strain (Figure 3).

\subsection{Population Differentiation $\left(\mathrm{F}_{S T}\right)$}

Pairwise population $\left(\mathrm{F}_{S T}\right)$ was calculated from filtered SNPs to investigate population differentiation among different strains of Tswana chickens. $\mathrm{F}_{S T}$ values are shown in Table 3 and varied from 0.013 to 0.084 . According to [30] Hussein et al., it is generally recognized that $\mathrm{F}_{S T}$ values ranging from 0 to 0.05 indicate low genetic differentiation; those ranging between 0.05 and 0.15 medium differentiation; those between 0.15 and 0.25 indicate big differentiation and those values above 0.25 indicate very big genetic differentiation. There was low genetic differentiation between the normal strain of Tswana chicken and the commercial broiler chicken (0.031). There was, however, moderate genetic differentiation between the dwarf strain of Tswana chicken and commercial broiler chicken and between the naked neck strain of Tswana chicken and the commercial broiler chicken (0.084, 0.054 respectively).

Low genetic differentiation occurred between dwarf and naked neck (0.040), dwarf and normal (0.040), and between normal and naked neck (0.013) strains of Tswana chickens. Pairwise genetic distances between different strains of Tswana chickens and commercial broiler are highly correlated with genetic differentiation values. Generally, the higher the genetic differentiation between strains the higher the genetic distances. The low genetic distances occurred between normal and naked neck strains of Tswana chickens (0.013) and between normal strain of Tswana chicken and commercial broiler chicken (0.032). Moderate genetic distance occurred between naked neck and dwarf (0.042) and between normal and dwarf (0.043) strains of Tswana chickens. High genetic distances occurred between naked neck and commercial broiler (0.057) and between dwarf and commercial broiler (0.092). Generally, less genetic differentiation and fewer genetic distances occurred between the three strains of indigenous Tswana chickens as compared to between the commercial broiler and the three strains of Tswana chickens. The less genetic differentiation and genetic distances between the three strains of Tswana chickens support the hypothesis of closer evolutionary history of common origin of the three strains of Tswana chickens. Generally higher genetic differentiation and genetic distance between strains of

Table 3. Pairwise genetic differentiation $\left(\mathrm{F}_{S T}\right)$ values (below diagonal) and genetic distance (above diagonal) between four (4) chicken populations in Kweneng and Southern districts of Botswana.

\begin{tabular}{ccccc}
\hline Population & Broiler & Dwarf & Naked neck & Normal \\
\hline Broiler & 0 & 0.092 & 0.057 & 0.032 \\
Dwarf & 0.084 & 0 & 0.042 & 0.043 \\
Naked neck & 0.054 & 0.040 & 0 & 0.013 \\
Normal & 0.031 & 0.041 & 0.013 & 0
\end{tabular}


indigenous Tswana chickens and the commercial broiler chickens might be since indigenous Tswana chickens are not intensively selected while commercial broilers are heavily selected during their developmental process.

\subsection{Linkage Disequilibrium (LD) Estimates and the Effect of Strain}

A summary of $r^{2}$ values for the 28 chicken autosomal chromosomes in the three strains of Tswana chickens and commercial broiler chicken are shown in Table 4. Overall population LD over all chromosomes ranged from 0.067 to 0.241 in indigenous Tswana chickens and from 0.342 to 0.407 in commercial broiler chicken and averaged $0.128 \pm 0.056$ and $0.375 \pm 0.0152$ in indigenous Tswana chickens and commercial broiler chicken, respectively. The highest LD values were found in chromosome 16 in the normal and naked neck strains of Tswana chickens and in chromosome 23 in the dwarf strain of Tswana chicken. Higher $\mathrm{LD}$ values on chromosome 16 for naked neck and normal strains of Tswana chickens are consistent with [16] Khanyile et al. who also reported higher LD values in chromosome 16 for both village chickens and conservation flocks. The lowest LD values were found in chromosome 23 in the naked neck and normal strains of Tswana chickens and in chromosome 25 in the dwarf strain of Tswana chicken. Low LD values on chromosome 25 in the dwarf strain of Tswana chicken are consistent with [16] Khanyile et al. who also reported low LD values on chromosome 25 for both village and conservation flocks. Chromosome 17 had high LD in the commercial broiler strain while chromosome 16 had low LD. Consistent with [16] Khanyile et al., the current study also indicates that evolutionary forces affecting LD act differently on different chromosomes and different strains. Commercial broiler chicken had higher LD compared to the three strains of indigenous Tswana chickens probably because of the effects of artificial selection for higher meat yield. On the other hand, natural selection could be a major evolutionary force in the three strains of Tswana raised under free-running management systems with minimal artificial selection [16]. There was no significant difference in LD between the normal and naked neck strains of Tswana chickens. However, the two strains of Tswana chickens had significantly lower LD than dwarf strain of Tswana chicken. Of the four chicken strains, the commercial broiler chicken had significantly higher LD compared to the three strains of Tswana chickens.

Higher LD in commercial broiler compared to the three strains of Tswana chickens is consistent with [16] Khanyile et al. who found significantly higher LD in conservation flocks compared village chicken populations kept by small holder farmers. Differences in LD between commercial broiler and the three strains of Tswana chickens could be due to their different evolutionary histories under the influence of random genetic drift, selection, and mutations [16]. The dwarf strain of Tswana had higher LD across the 28 autosomal chromosomes compared to normal and naked neck strains of Tswana chickens. Higher LD in the dwarf strain compared to the naked neck and normal strains of Tswana 
Table 4. Linkage disequilibrium $\left(\mathrm{r}^{2}\right)$ of three indigenous Tswana chickens and commercial broilers in Kweneng and southern districts of Botswana.

\begin{tabular}{|c|c|c|c|c|}
\hline Chromosome No. & Normal & Naked neck & Dwarf & Broiler \\
\hline 1 & $0.089 \pm 0.137$ & $0.093 \pm 0.138$ & $0.209 \pm 0.225$ & $0.395 \pm 0.331$ \\
\hline 2 & $0.090 \pm 0.144$ & $0.095 \pm 0.144$ & $0.202 \pm 0.221$ & $0.368 \pm 0.319$ \\
\hline 3 & $0.089 \pm 0.131$ & $0.097 \pm 0.136$ & $0.194 \pm 0.213$ & $0.371 \pm 0.320$ \\
\hline 4 & $0.089 \pm 0.138$ & $0.096 \pm 0.142$ & $0.220 \pm 0.229$ & $0.368 \pm 0.314$ \\
\hline 5 & $0.084 \pm 0.129$ & $0.084 \pm 0.128$ & $0.188 \pm 0.210$ & $0.366 \pm 0.317$ \\
\hline 6 & $0.085 \pm 0.125$ & $0.092 \pm 0.129$ & $0.219 \pm 0.235$ & $0.375 \pm 0.322$ \\
\hline 7 & $0.084 \pm 0.132$ & $0.087 \pm 0.133$ & $0.219 \pm 0.230$ & $0.374 \pm 0.320$ \\
\hline 8 & $0.114 \pm 0.185$ & $0.107 \pm 0.166$ & $0.204 \pm 0.240$ & $0.391 \pm 0.334$ \\
\hline 9 & $0.078 \pm 0.119$ & $0.083 \pm 0.119$ & $0.215 \pm 0.221$ & $0.363 \pm 0.320$ \\
\hline 10 & $0.077 \pm 0.115$ & $0.086 \pm 0.119$ & $0.199 \pm 0.217$ & $0.381 \pm 0.320$ \\
\hline 11 & $0.098 \pm 0.155$ & $0.104 \pm 0.160$ & $0.222 \pm 0.237$ & $0.399 \pm 0.331$ \\
\hline 12 & $0.083 \pm 0.123$ & $0.091 \pm 0.128$ & $0.199 \pm 0.216$ & $0.373 \pm 0.321$ \\
\hline 13 & $0.088 \pm 0.135$ & $0.090 \pm 0.132$ & $0.213 \pm 0.231$ & $0.384 \pm 0.321$ \\
\hline 14 & $0.089 \pm 0.141$ & $0.096 \pm 0.141$ & $0.192 \pm 0.215$ & $0.373 \pm 0.321$ \\
\hline 15 & $0.105 \pm 0.153$ & $0.099 \pm 0.144$ & $0.208 \pm 0.229$ & $0.374 \pm 0.334$ \\
\hline 16 & $0.133 \pm 0.165$ & $0.146 \pm 0.159$ & $0.206 \pm 0.244$ & $0.342 \pm 0.294$ \\
\hline 17 & $0.089 \pm 0.143$ & $0.100 \pm 0.154$ & $0.216 \pm 0.231$ & $0.407 \pm 0.334$ \\
\hline 18 & $0.077 \pm 0.113$ & $0.083 \pm 0.116$ & $0.195 \pm 0.208$ & $0.363 \pm 0.312$ \\
\hline 19 & $0.079 \pm 0.125$ & $0.085 \pm 0.130$ & $0.184 \pm 0.205$ & $0.361 \pm 0.316$ \\
\hline 20 & $0.095 \pm 0.144$ & $0.102 \pm 0.145$ & $0.200 \pm 0.222$ & $0.371 \pm 0.318$ \\
\hline 21 & $0.086 \pm 0.130$ & $0.088 \pm 0.131$ & $0.230 \pm 0.236$ & $0.378 \pm 0.319$ \\
\hline+22 & $0.087 \pm 0.141$ & $0.082 \pm 0.134$ & $0.183 \pm 0.205$ & $0.410 \pm 0.335$ \\
\hline 23 & $0.067 \pm 0.102$ & $0.073 \pm 0.108$ & $0.241 \pm 0.240$ & $0.361 \pm 0.317$ \\
\hline 24 & $0.081 \pm 0.132$ & $0.089 \pm 0.138$ & $0.200 \pm 0.221$ & $0.366 \pm 0.312$ \\
\hline 25 & $0.069 \pm 0.104$ & $0.074 \pm 0.108$ & $0.172 \pm 0.198$ & $0.358 \pm 0.308$ \\
\hline 26 & $0.074 \pm 0.107$ & $0.081 \pm 0.113$ & $0.196 \pm 0.212$ & $0.391 \pm 0.329$ \\
\hline 27 & $0.082 \pm 0.130$ & $0.085 \pm 0.127$ & $0.194 \pm 0.216$ & $0.370 \pm 0.333$ \\
\hline 28 & $0.074 \pm 0.122$ & $0.090 \pm 0.136$ & $0.199 \pm 0.222$ & $0.371 \pm 0.320$ \\
\hline Overall means & $0.087 \pm 0.002^{\mathrm{a}}$ & $0.092 \pm 0.002^{\mathrm{a}}$ & $0.204 \pm 0.002^{\mathrm{b}}$ & $0.375 \pm 0.002^{\mathrm{c}}$ \\
\hline
\end{tabular}

chickens is consistent with its low diversity as measured by both observed and expected heterozygosity $\left(\mathrm{H}_{\mathrm{o}}\right.$ and $\mathrm{H}_{\mathrm{e}}$ ) and its low effective size (Figure 4). Lower effective population size in the dwarf compared to the normal and naked neck strains of Tswana chickens are consistent with the actual population of dwarf chicken in the general population of Tswana chickens. The general population of Tswana chickens comprises mostly the normal strain followed by naked neck strain and lastly the dwarf strain of Tswana chickens [13]. Across the four strains under investigation the normal strain had the lowest LD (0.087) and the commercial broiler had the highest LD (0.375). 


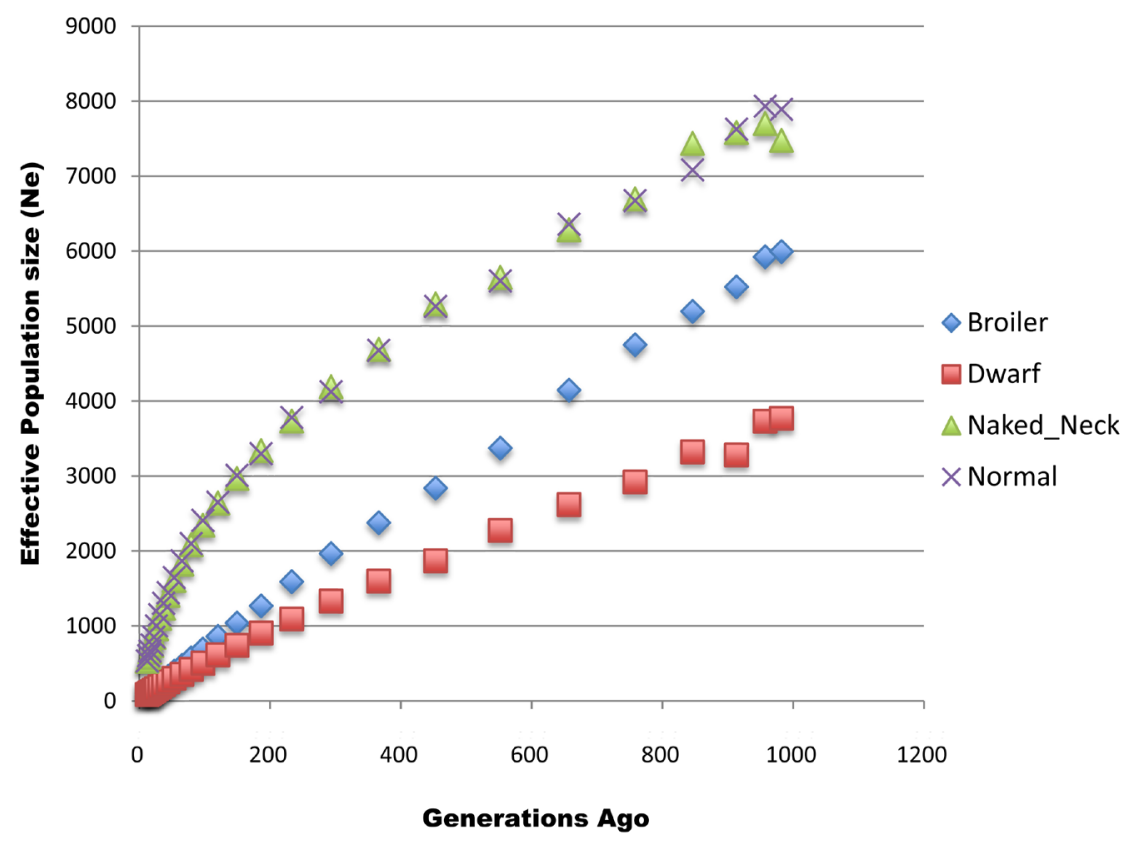

Figure 4. The effective population size of normal, naked neck, dwarf strains of Tswana chickens and Broiler breed in Kweneng and southern districts of Botswana from 982 to 12 generations ago.

\subsection{Trends in Effective Population Size $\left(\mathrm{N}_{\mathrm{e}}\right)$}

Plots of estimated effective population size $\left(\mathrm{N}_{\mathrm{e}}\right)$ at $t$-generations ago for various strains of Tswana chickens and commercial broiler chickens are shown in Figure 4. The adjusted Linkage Disequilibrium (LD) based estimates of $\mathrm{N}_{\mathrm{e}}$ indicated low effective population sizes of 123, 738 and 748 for dwarf, naked neck, and normal strains of Tswana chickens, respectively, 19 generations ago. Higher $\mathrm{Ne}$ of 613,2640, 2650 was found for the dwarf, naked neck, and normal strains of Tswana chickens respectively, 120 generations ago. The effective population size $\left(\mathrm{N}_{\mathrm{e}}\right)$ was even higher with values of 3768, 7477 and 7891 for the three strains of Tswana chickens, respectively, 982 generations ago. The commercial broiler had $\mathrm{N}_{\mathrm{e}}$ of 147, 859 and 5994 at 19, 120 and 982 generations ago, respectively. The graphs illustrate a steady decrease in $\mathrm{N}_{\mathrm{e}}$ from over 980 to below 20 generations ago in both indigenous Tswana chickens and commercial broiler chickens. The naked neck and normal strains of indigenous Tswana chickens showed similar patterns of decreasing $\mathrm{N}_{e}$ values but had higher $\mathrm{N}_{\mathrm{e}}$ values than the dwarf strain. In comparison with the three strains of indigenous Tswana chickens, the commercial broiler chicken had higher $\mathrm{N}_{\mathrm{e}}$ values at all generations than the dwarf strain. The LD patterns are consistent with effective population size and diversity patterns in the commercial broiler and the three strains of Tswana chickens. Generally, higher LD patterns are associated with low effective population sizes and lower diversity in the populations.

\section{Conclusion}

The naked neck, normal and dwarf strains of Tswana chicken had similar, mod- 
erate genetic diversity measures (observed and expected heterozygosity which was significantly higher than those of the modern commercial broiler chicken). The principal component analysis (PCA) which was used to get an insight into the population structure of indigenous Tswana chickens and the commercial broiler revealed a set of three clusters or wild ancestors. The commercial broiler clustered separately in one group. The dwarf strain clustered separately in another group and the naked neck and normal strains clustered together in the last group. The clustering pattern was confirmed by less genetic differentiation and less genetic distances between the naked neck and normal strains of Tswana chicken than between the two strains and the dwarf strain of Tswana chicken. Linkage disequilibrium patterns across chromosomes were also similar between the naked neck and normal strains of Tswana chicken and different from those of the dwarf strain of Tswana chicken. The separate clustering of the dwarf strain from the rest of Tswana chicken strains and different linkage disequilibrium in the dwarf than in the other two strains of Tswana chicken suggests significant genetic uniqueness of the dwarf strain and very close genetic similarities between the normal and naked neck strains.

\section{Acknowledgements}

The authors would like to thank Botswana University of Agriculture and Natural Resources for funding the study. The authors would also like to thank Agricultural Research Council, Biotechnology Platform, Pretoria, South Africa, for availing all their genotyping equipment and for assisting with the genotyping and analysis of SNP data.

\section{Ethics Approval}

The keeping of the research birds was approved by the Animal Research Ethics Committee of Botswana University of Agriculture and Natural Resources (Approval No. 2020-13), which conforms to the guidelines and the use of research animals.

\section{Conflicts of Interest}

The authors declare that the research was conducted in the absence of any commercial relationships that could be construed as a potential conflict of interest.

\section{References}

[1] Padhi, M.K. (2016) Importance of Indigenous Breeds of Chicken for Rural Economy and Their Improvements for Higher Production Performance. Scientifica, 2016, Article ID: 2604685. https://doi.org/10.1155/2016/2604685

[2] Crawford, R.D. (1992) A Global Review of the Genetic Resources of Poultry. In: Hodges, J., Eds., The Management of Global Animal Genetic Resources. Proceedings of an FAO Expert Consultation, Rome, April 1992, 205-211.

[3] Igbal, S, Pampori, Z.A. and Hasin, D. (2009) Carcass and Egg Characteristics of Indigenous Chicken of Kashmir (Kashmir Favorella). Indian Journal of Animal Re- 
search, 43, 194-196.

[4] Jaturasitha, S., Srinkanchai, T., Kreuzer, M. and Wicke, M. (2008) Differences in Carcass and Meat Characteristics between Chicken Indigenous to Northern Thailand (Black-Boned and Thai Native) and Imported Extensive Breeds (Bresse and Rhode Island Red). Poultry Science, 87, 160-169.

https://doi.org/10.3382/ps.2006-00398

[5] Mtileni, B.J., Muchadeyi, F.C., Maiwashe, A., Phitsane, P.M., Halimani, T.E., Chimonyo, M. and Dzama, K. (2009) Characterisation of Production Systems for Indigenous Chicken Genetic Resources of South Africa. Applied Animal Husbandry and Rural Development, 2, 18-22.

[6] Kgwatalala, P.M., Nogayagae, M and Nsoso, S.J. (2012) Growth Performance of Different Strains of Indigenous Tswana Chickens under Intensive Management System. African Journal of Agricultural Research, 7, 2438-2445.

https://doi.org/10.5897/AJAR11.1220

[7] Dessie, T., Taye, T., Dana, N., Ayalew, W. and Hanotte, O. (2011) Current State of Knowledge on Phenotypic Characteristics of Indigenous Chickens in the Tropics. World's Poultry Science Journal, 67, 507-516. https://doi.org/10.1017/S0043933911000559

[8] Riise, J.C., Permin, A. and Kryger, K.N. (2005) Strategies for Developing Family Poultry Production at VILLAGE level-Experiences from West Africa and Asia. World's Poultry Science Journal, 61, 15-22. https://doi.org/10.1079/WPS200437

[9] Sonaiya, E.B. and Swan, S.E.J. (2004) Small-Scale Poultry Production, Technical Guide Manual. FAO Animal Production and Health, 1.

[10] Desta, T.T. (2015) Phenomic and genomic landscape of Ethiopian Village Chickens. PhD Thesis, University of Nottingham, UK.

[11] Moreki, J.C. (1997) Village Poultry Production in Fifteen Villages of Botswana: Phase I (Surveys) of the Poultry Development Project, AG. 205 (51/205). Department of Animal Health and Production, Ministry of Agriculture, Gaborone.

[12] Badubi, S.S., Rakereng, $M$ and Marumo, M. (2006) Morphological Characteristics and Feed Resources Available for Indigenous Chickens in Botswana. Livestock Research for Rural Development, 18.

https://lrrd.cipav.org.co//rrd18/1/badu18003.htm

[13] Machete, J.B., Kgwatalala, P.M., Nsoso, S.J., Moreki, J.C., Nthoiwa, P.G and Aganga, A.O. (2021) Phenotypic Characterisation (Qualitative Traits) of Various Strains of Indigenous Tswana Chickens in Kweneng and Southern Districts of Botswana. International Journal of Livestock Production, 12, 28-36. https://doi.org/10.5897/IJLP2020.0745

[14] Machete, J.B., Nsoso, S.J., Kgwatalala, P.M., Moreki, J.C. and Aganga, A.O. (2017) Phenotypic Characterization of Tswana Chickens Based on Quantitative Traits in Kweneng and Southern districts, Botswana. Livestock Research for Rural Development, 29. http://www.lrrd.org/lrrd29/7/jmsm29132.html

[15] Kgwatalala, P.M., Bolowe, A.M., Thutwa, K. and Nsos, S.J. (2013) Carcass Traits of Naked-Neck, Dwarf and Normal Strains of Indigenous Tswana Chickens under an Intensive Management System. Agriculture and Biology Journal of North America. http://www.scihub.org/ABJNA https://doi.org/10.5251/abjna.2013.4.4.413.418

[16] Khanyile, K.S., Dzomba, E.F. and Muchadeyi, F.C. (2015) Population Genetic Structure, Linkage Disequilibrium and Effective Population Size of Conserved and Extensively Raised Village Chicken Populations of Southern Africa. Frontiers in Genetics, 6, 1-11. https://doi.org/10.3389/fgene.2015.00013 
[17] Illumina, Inc. (2018) Infinium Assay Compatible with the Illumina HiScan SQ Genotyping Platform. https://www.illumina.com/

[18] Purcell, S., Neale, B., Todd-Brown, K., Thomas, L., Ferreira, M.A.R., Bender, D., Maller, J., Sklar, P., de Bakker, P.I.W., Daly, M.J. and Sham, P.C. (2007) PLINK: A Tool Set for Whole-Genome Association and Population-Based Linkage Analyses. American Journal of Human Genetics, 81, 559-575. https://doi.org/10.1086/519795

[19] Golden Helix Inc. (2014) SNP and Variation Suite (Version 8.1) [Software]. MT, Bozeman. http://www.goldenhelix.com

[20] Alexander, D.H., Novembre, J. and Lange, K. (2009) Fast Model-Based Estimation of Ancestry in Unrelated Individuals. Genome Research, 19, 1655-1664.

https://genome.cshlp.org/ https://doi.org/10.1101/gr.094052.109

[21] Pembleton, L.W., Cogan, N.O and Forster, J.W. (2013) StAMPP: An R Package for Calculation of Genetic Differentiation and Structure of Mixed-Ploidy Level Populations. Molecular Ecology Resources, 13, 946-952.

https://pubmed.ncbi.nlm.nih.gov/23738873/ https://doi.org/10.1111/1755-0998.12129

[22] Weir, B.S. and Cockerham, C.C. (1984) Estimating F-Statistics for the Analysis of Population Structure. Evolution, 38, 1358-1370. https://doi.org/10.1111/j.1558-5646.1984.tb05657.x

[23] Lu, D., Sargolzaei, M., Kelly, M., Li, C.X., Van der Voort, G., Wang, Z.Q., et al. (2012) Linkage Disequilibrium in Angus, Charolais, and Crossbred Beef Cattle. Frontiers in Genetics, 3, 10. https://doi.org/10.3389/fgene.2012.00152

[24] Qanbari, S., Hansen, M., Weigend, S., Preisinger, R., and Simianer, H. (2010) Linkage Disequilibrium Reveals Different Demographic History in Egg Laying Chickens. BMC Genomics, 11, Article No. 103. https://doi.org/10.1186/1471-2156-11-103

[25] Corbin, L., Blott, S., Swinburne, J., Vaudin, M., Bishop, S., and Woolliams, J. (2010) Linkage Disequilibrium and Historical Effective Population Size in the Thoroughbred Horse. Animal Genetics, 41, 8-15. https://doi.org/10.1111/j.1365-2052.2010.02092.x

[26] Ensembl (2013) Chicken Genome. http://www.ensembl.org/Gallus_gallus/Location/Genome

[27] Hillier, L.W., Graves, T.A. and Wilson, R.K. (2005) Generation and Annotation of the DNA Sequences of Human Chromosomes 2 and 4. Nature, 434, 724-731. https://doi.org/10.1038/nature03466

[28] Al-Atiyat, R.M. and Abudabos, A.M. (2014) Molecular Diversity of Different Chicken Populations Based on Nucleotide Sequencing. Journal of Food, Agriculture \& Environment, 12, 379-382.

[29] Mwacharo, J.M., Bjørnstad, G., Han, J.L. and Hanotte, O. (2013) The History of African Village Chickens: An Archaeological and Molecular Perspective. The African Archaeological Review, 30, 97-114. https://doi.org/10.1007/s10437-013-9128-1

[30] Hussein, A.O., Hameed, I.H., Jasim, H. and Kareem, M.A. (2015) Determination of Alkaloid Compounds of Ricinus Communis by Using Gas Chromatography-Mass Spectroscopy (GC-MS). Journal of Medicinal Plants Research, 9, 349-359. https://doi.org/10.5897/JMPR2015.5750 